\title{
As INSTITUIÇões PSicanalíticas E SuAs FoRMAÇÕES \\ SINTOMÁTICAS
}

Betty Bernardo Fuks ${ }^{1}$

\section{Resumo}

A autora aborda o tema do ensino e transmissão da psicanálise a partir da famosa frase, atribuída a Freud por ocasião de sua chegada aos Estados Unidos em 1909, "Eles não sabem o que estamos Ihes trazendo: a peste", propõe refletir sobre os impasses sintomáticos das instituições psicanalistas frente à realidade do inconsciente.

PalaVRas-Chaves: Peste. Inconsciente. Instituição Psicanalítica. Formações Sintomáticas.

1 Psicanalista. Escritora. Docente do Programa de Pós-graduação em Psicanálise, Saúde e Sociedade da Universidade Veiga de Almeida. Editora da revista online Trivium: estudos interdisciplinares. ORCID: https://orcid.org/0000-0002-5325-7382 . 


\section{INTRODUÇÃO}

Em 27 de agosto de 1909 Freud, acompanhado de seus discípulos Gustav Jung e Sandor Ferenczi, embarca no transatlântico George Washington aportado em Bremen (Alemanha), rumo aos Estados Unidos, para proferir uma série de conferências na Clarck University de Worceste. Durante algum tempo acreditou-se que sete dias após o embarque, ao avistar a Estátua da Liberdade no porto de Nova York, o inventor da psicanálise teria proferido uma frase que se tornou célebre: "Eles não sabem o que estamos Ihes trazendo: a peste". Entretanto, foi Jacques Lacan quem, décadas depois da tournée de Freud aos Estados Unidos, tornou pública essa frase hipotética, numa conferência proferida em Viena em 1955, comentando tê-la ouvido diretamente de Jung. Assumindo abertamente a veracidade da confissão do colega suíço, Lacan expõe, então, sua interpretação sobre o dito: ao equiparar a psicanálise à uma epidemia, Freud "havia acreditado que [ela] seria uma revolução para a América, e, na realidade, a América é que tinha devorado sua doutrina, retirando-lhe seu espírito subversivo" (ROUDINESCO \& PLON, 1998, p. 195).

$\mathrm{O}$ fato de muitos historiadores renomados do freudismo tenham assegurado que a frase correta enunciada por Freud, ao chegar a Nova York, tenha sido simplesmente - "Eles ficarão surpresos quando souberem o que teremos a dizer" -, nada impede de reconhecer que o significante "peste", enunciado por Lacan, está plenamente de acordo com o conhecido temor de Freud de que a psicanálise não fosse banalizada pelo sucesso que estava obtendo nos Estados Unidos. A preocupação do mestre de Viena girava em torno da ideia de que sua disciplina pudesse ser adaptada "ao way of life americano, com as simplificações e as distorções que disso derivam" (Chinalli , 2020).

Independente do imbróglio em torno do dito "Eles não sabem o que estamos Ihes trazendo: a peste", decidi usá-lo como bordão à minha reflexão sobre a demanda histérica dos analistas e obsessivização do ensino da psicanálise nas instituições psicanalíticas. Via de regra a maioria dessas instituições imprimem na formação de seus analistas um processo de colonização através da língua vinda do Outro técnicoteórico, fato esse que impede o enodamento necessário entre o ensino e a transmissão no campo psicanalítico. 


\section{DA Primeira Tentativa de InStitucionalizaÇão}

O nascimento da psicanálise acontece no momento em que Freud faz uma ruptura epistemológica anulando os discursos precedentes pela sistematização da teoria da prática psicanalítica. O discurso psiquiátrico era totalmente dominado por um ideal de conhecimento máximo, de verdade absoluta e o que Freud vai desvelar, a partir de sua escuta clínica, é que o Inconsciente denuncia a morte de uma verdade finalizada, estática, construída por um pequeno número de leis simples e imutáveis. $\mathrm{Na}$ psicanálise, trata-se de perceber o comportamento de uma realidade distinta, insubmissa, tanto a nossas crenças e ambições, quando a nossas esperanças. Ao objeto por ela interrogado - Das Ding - não faltam meios para refutar hipóteses plausíveis e sedutoras. A cena analítica se constitui num lugar em que o paciente deixa de ser julgado em nome de um saber preexistente, para falar ele próprio de seu saber "desconhecido". Cura e pesquisa convergem ininterruptamente na obra freudiana e aqueles analistas que tomam por herança este legado em sua prática terão de trilhar o mesmo caminho - cura e pesquisa - para que a psicanálise perdure.

É nesse sentido que a intervenção de Jacques Lacan, como veremos mais adiante, foi crucial à psicanálise. Além de ter colocado alguns conceitos da teoria freudiana em questão, o mestre de Paris se debruçou sobre a essência mesma da psicanálise, condenando aqueles que fizeram dela uma simples técnica em detrimento da nova prática de discurso científico inaugurada por Freud: a ciência psicanalítica faz falar, faz falarem sujeitos sobre uma verdade, mas não toda. Reorientando a psicanálise para o real, onde jamais haverá a última resposta, redefine o Inconsciente como aquilo que estará sempre por vir, constituindo-se a psicanálise, então não só num saber sobre o Inconsciente com também num saber inconsciente. ${ }^{2}$

Muito cedo Freud percebeu que a psicanálise enquanto ciência fazia parte do complexo da cultura e, por isso mesmo, deveria produzir a cada momento histórico suas próprias normas e verdades sem, entretanto, escapar de seu objeto, o que

\footnotetext{
2 Para melhor esclarecimento sobre a questão da ciência voltada ao real remetemos o leitor à filósofa das ciências Isabelle Stengers que, junto com o químico Ylia Prigogine, nos fala da possibilidade de uma ciência criativa do acaso e das circunstâncias. O cientista visando ao real, deve procurar integrar na ciência questões novas que o universo "fragmentado, rico de diversidades qualitativas e de surpresas potenciais" Ihe coloca.
} 
significaria seu próprio final. Neste sentido, o criador da psicanálise era muito pouco idealista: sabia que a psicanálise não poderia fugir às vicissitudes da história política e econômica da civilização, nem tampouco deixar de dialogar com outras disciplinas como a linguística, a filosofia, o mito, a biologia, a história das civilizações, a estética, o direito, a sociologia e a pedagogia (FREUD, 1913).

Para preservar a prática da psicanalítica de desvios de cunho ideológico, político ou mesmo filosófico, decide fundar, uma sociedade onde fosse possível haver trocas de ideias entre pares. Assim, evitaria também descaminhos teóricos, fazendo frente principalmente à resistência daqueles que não reconheciam ou mesmo repudiavam sua nova ciência. Freud acreditava que a instituição psicanalítica poderia não somente preservar sua doutrina como também a lançar ao mundo para que fosse reconhecida como uma nova ciência e não como uma nova Welttanschaung. Agrupados em torno de uma causa comum, os analistas militariam por tornar a psicanálise universal, desalojando-a de Viena.

Desta forma, Freud agregou à teoria do Inconsciente uma "política" que denota a maneira como a psicanálise concebe as modalidades de seu poder e a organização de suas instituições (ROUDINESCO, 1989, p. 84). Neste momento de fundação do movimento psicanalítico, a história da descoberta da psicanálise e a história de suas instituições se interligam, embora a primeira não possa ser confundida com a segunda, como atesta o texto "História do movimento psicanalítico" (1914). Aqui Freud confessa sua decepção para com o rumo do movimento e aponta o deslocamento da resistência externa ao corpus da psicanálise para dentro dele: "Do mesmo modo que os meus adversários iriam descobrir que não é possível lutar contra a corrente do novo movimento, assim também eu acabaria percebendo que este não seguiria a direção que eu desejava vê-lo seguir" (FREUD, 1914, p. 57).

Mesmo com toda a decepção, Freud insistiu no projeto da institucionalização da psicanálise, pois, como diz nesse mesmo texto, "a psicanálise é criação minha" (FREUD, 1914, p. 16); o que o fazia se sentir responsável por seu futuro. Assim, depois de marcar as fronteiras da psicanálise, indica uma modalidade de assegurá-la. Por relação às fronteiras deixa claro que a psicanálise exige fidelidade à teoria da sexualidade infantil, à teoria do recalque e aos fatos da resistência e da transferência. No que se refere à modalidade de expansão da descoberta do Inconscienrte, propõe o agrupamento daqueles que supostamente estariam de acordo com as três 
exigências citadas. Se as fronteiras marcam o irredutível da teoria do Inconsciente, a pertença institucional deixa entrever uma questão de psicologia do grupo (ideal comum, líder carismático, hipnose etc.).

Já em seus primórdios, o processo de institucionalização psicanálise cria uma discrepância entre aquilo o que propõe enquanto movimento e o uso que dela farão os seguidores de Freud quando a fundação da IPA. Fortaleceu-se a instituição psicanalítica através de vínculos indentificatórios em busca de ideias, em detrimento do fortalecimento da psicanálise enquanto um saber que visava a abordar um ponto a partir do qual o real é passível de alguma designação. Desta forma, o "sucesso conquistado pela doutrina psicanalítica andou de braços dados com o fracasso de um movimento já à mercê do gigantismo" (ROUDINESCO, 1989, p. 104) e dos efeitos da psicologia das massas. Freud insistiu, entretanto, na institucionalização da psicanálise apesar de ter percebido o significado e o preço a se pagar por sua institucionalização. Eles não sabem o que estamos lhe trazendo: a peste.

Enquanto vivo Freud, desde o lugar de "mestre sem mando", como identificou Elizabeth Roudinesco (1989, vol II, p. 243), utiliza-se da política de deixar a outros os assuntos de instituição e preocupa-se apenas em velar pela doutrina. Conhecemos as histórias dos rompimentos que efetuou com todos aqueles que não se mantiveram fiéis a seu texto. O rompimento com Jung, em que depositou a esperança de tirar a psicanálise do gueto judaico, revela que a fidedignidade sobre a teoria sobrepujava sua institucionalização. Freud jamais autorizou que o analista se servisse do nome da psicanálise em teorias por ela mesma refutáveis. Numa demonstração de coragem absoluta e honestidade intelectual, já no fim da vida, escreve um texto - "Análise terminável e interminável" (1937) - no qual testemunha os limites de sua descoberta até onde ele mesmo pudera chegar. Utilizando-se do próprio aparelho conceitual da psicanálise na análise desses limites lega ao mundo a verdadeira estrutura de sua descoberta: abertura à escuta de verdade impossível é o que permite minimamente o trabalho do analista, em sua profissão assim também impossível.

Quanto a transmissão da psicanálise, a obra derradeira "O homem Moisés e o monoteísmo" (1939), testemunha a preocupação do autor para com a sobrevivência do ensino e transmissão da psicanálise. Ao citar a figura Yohanán bem Zakkay, o rabino talmudista que após a destruição do Templo de Salomão e da perda de Jerusalém pediu permissão para abrir uma escola de estudos da Torá na cidade de Jabné, Freud revela sua confiança de que a transmissão e o ensino dos conceitos 
psicanalíticos, todos eles determinados pelo saber inconsciente, deveriam de ser passíveis plenamente articulados às outras gerações de analistas. Para tanto, o analista deve abrir mão de garantias em favor da letra que não para de não se inscrever. Eles não sabem o que estamos lhe trazendo: a peste

Os membros da IPA, após a morte de Freud, foram se afastando da causa do fundador da psicanálise progressivamente rumando para a construção de uma teoria da técnica e suas relações com a política institucional de formação dos analistas. Com isto, instalou-se um campo favorável a que alguns seguidores de Freud pudessem rasurá-la sob a máscara de teorias que fugiam à sua própria essência ou sob a forma de um tecnicismo obturante que impediu novas descobertas por longos anos no campo psicanalítico. O que se pode verificar é que qualquer cerimonial de uma pretensa técnica psicanalítica, parodiando o dito de Freud em "Atos obsessivos e práticas religiosas" (1907, p.123), é "uma caricatura, ao mesmo tempo cômica e triste, de uma religião particular", a do analista. Eles não sabem o que estamos Ihe trazendo: a peste.

\section{O Retorno a Freud e a Política do Inconsciente.}

1964. J. Lacan, dando fim a um longo período de batalha travada com a IPA em favor do retorno à experiência germinal de Freud, que culminaria em sua expulsão daquela instituição, funda a Escola Freudiana de Paris, por ele mesmo dissolvida antes de morrer. Propõe o famoso "retorno a Freud" visando não apenas resgatar a metapsicologia freudiana através da revisão de seus quatro conceitos fundamentais (inconsciente, repetição, transferência e pulsão), com também a acabar com o tecnicismo obsessivo que estava se tornando um antídoto da peste. Retornar a Freud significou reinventar a psicanálise, psicologizada pela teoria da técnica e reduzida ao exercício de sugestão. Com isso automaticamente colocou em xeque os princípios do poder na direção da cura (LACAN, [1958] 1998), atingindo a clínica da Psicologia do Ego em sua prática de limitar o tratamento psicanalítico à análise das resistências e a escuta da transferência a uma relação dual.

Foi preciso sustentar que a clínica psicanalítica, conforme Freud demonstrou a Breuer por ocasião do caso Anna O., exige do analista uma posição terceira, porque o drama do sujeito freudiano não diz respeito ao eu do paciente e muito ao do analista. 
Assim, a psicanálise se distingue de outras práticas terapêuticas, pois sua direção é não somente a cura, mas também a possibilidade de o sujeito ser reconhecido em sua realidade psíquica, que designa o desejo inconsciente e as fantasias a ele ligadas.

$\mathrm{Na}$ distinção entre Trieb e Instinkt, Lacan, no texto Do "Trieb de Freud e do desejo do analista", esclarece que o primeiro, "tal como construído por Freud a partir da experiência do Inconsciente, proíbe o pensamento psicologizante, o recurso ao instinto [...]" (Lacan, 1964 [1998], p. 865). Trata-se, o instinto, de uma noção estranha ao aparelho conceitual da psicanálise, utilizada largamente por aqueles que se desviaram da descoberta freudiana. Para evitar outras distorções, Lacan vincula as pulsões, "nossa mitologia", no dizer de Freud, ao desejo do analista, a lei que instaura a diferença entre a prática psicológica fundamentada na noção de maturação de instinto e a práxis de ouvir as pulsões em sua inesgotável melodia. Aqueles que tomam a psicanálise como referência, Lacan propõe em outro de seus seminários uma ética: a do desejo, "[...] desejo de nada que possa ser nomeado [...]" (Lacan, 1962-63 [1982], p. 120), no sentido de que nada possa, em sendo nomeado, cristalizar-se enquanto seu objeto. Portanto, a ética da psicanálise diz respeito somente ao comprometimento do analista com a escuta aberta ao inconsciente.

Justamente, a proposta de Lacan é que o inconsciente, com sua força subversiva seja escutado também desde dentro da instituição. Daí propor que aposta freudiana na institucionalização da psicanálise deveria de ser retomada sob a égide da "política do inconsciente" (Lacan, 1981, p. 14), e reencontrar, com isso, o desejo do analista dentro dela também. A esta vertente da psicanálise, sua inclusão no mundo através da institucionalização, denominará psicanálise em extensão, cuja raiz, deve ser procurada na experiência psicanalítica mesma, isto é, naquilo a que denominará psicanálise em intensão, a qualificação do analista daria para ocupar tal função.

Estamos diante de outras garantias: a formação do analista daria, não mais em termos burocráticos, como se dava na IPA, mas através do testemunho que o analista daria de sua própria análise e seu final. A diferença entre os membros, desta vez, se passaria no plano da teoria e não mais no da hierarquia dos membros. Com isto, uma mudança radical no ensino da instituição, numa estratégia de funcionamento em três lugares, ligando a psicanálise em intensão e em extensão: o seminário, lugar da transmissão do discurso da psicanálise, formalizado; o cartel, onde o analista, numa produção singular, anularia qualquer tentativa de ilusão da criação coletiva, que 
fatalmente levaria de volta ao corporativismo; e o passe, lugar de testemunho do que levou o analista a ser suporte do discurso psicanalítico.

Lacan, ele mesmo, elaborou a questão teórica sobre o final da análise, mas não conseguiu resolver os impasses criados pela teoria do passe, segundo a leitura de Moustapha Sofouan: "[...] a questão do saber como há um psicanalista é uma questão que se coloca mais ou menos nos mesmos termos do que se chama em lógica a questão da existência" (SOFOUAN, 1985, p. 61). A experiência do passe e seu fracasso institucional foi um dos motivos da derrocada da Escola, o que aponta que a teoria sobre o término de análise está em aberto, necessitando de melhor teorização sobre ela por parte dos analistas. Essa questão traz em seu bojo um impasse crucial - o manejo da transferência analítica nas análises dos analistas - que, a questão que pede a maior urgência de ser pensada, falada e teorizada, não só enquanto acréscimo à teoria psicanalítica, mas sobretudo para que a análise do analista seja uma experiência eficaz e bem sucedida no sentido de que possa lhe provocar o inesgotável desejo de saber sobre a Outra cena.

Durante sua permanência na Escola, Lacan logrou pôr em prática a democracia na instituição, mas formou-se em torno dele uma relação, como demonstra Roudinesco em a "História da Psicanálise na França", "quase que religiosa com sua pessoa e sua doutrina" (ROUDINESCO, 1990, vol. II, p. 127). O paradoxo é que para o próprio Lacan esse destino era absolutamente abominável. Legando aos analistas não só a recuperação do que estava perdido após a morte de Freud, como inovações teórico-técnicas da maior relevância, correu de todas as formas o risco de produzir elementos da teoria do Inconsciente, que recuperaram o vigor da subversão freudiana. Foi fiel ao que ouviu de Jung a respeito do que Freud teria dito ao entrar em solo americano: "Eles não sabem o que estamos lhe trazendo: a peste".

Triste destino o das grandes instituições psicanalíticas: morre seu fundador, seu chefe, e imediatamente o movimento começa a se descaracterizar, a perder sua virulência, seu caráter revolucionário, para transformar-se numa grande organização de massa, onde o investimento do analista fica dirigido à sustentação da instituição e não aos significantes da psicanálise. Freud denunciaria em 1926, numa entrevista a G. Viereck, o empobrecimento da psicanálise quando ligada a movimentos muito massificados: 
"A América fez poucas contribuições originais à psicanálise. Os americanos são divulgadores inteligentes, raramente pensadores criativos... A população [da psicanálise] leva à aceitação superficial, sem estudo sério..." (FREUD, 1937, p. 127). Vale a pena repetir, mais uma vez, o nosso bordão: "Eles não sabem o que estamos Ihe trazendo: a peste".

\section{Os Antídotos Atuais Contra a Peste}

Se a força da resistência externa à psicanálise ameaçou-a na aurora de sua fundação, hoje, passados quase cem anos da descoberta freudiana, enquanto o mundo a reconhece e ela aí garante seu vigor, torna-se não só patente quanto nos deixa perplexos e o retorno da resistência que se infiltra nas próprias instituições psicanalíticas, criadas justamente para servir e preservar a psicanálise. Por que então a força subversiva da teoria freudiana e a proposta lacaniana, não menos subversiva, de um novo modelo de instituição sob a égide da política do inconsciente não alcançou atravessar a totalidade das instituições atuais?

"Não admitimos de modo algum: não podemos perceber porque as instituições que nós mesmos criamos não são representantes de mais bem-estar e proteção[...]" (FREUD, 1930, p. 105). Nestes termos, Freud constata em Mal-estar na civilização o caráter não só enigmático quanto inaceitável da terceira fonte do sofrimento no homem, cuja origem é social. Ao longo do texto, Freud revela ao leitor uma antinomia entre sujeito e instituição; denuncia o caráter conservador desta e revela no homem o "desejo de inventar outras realidades..." (ROUDINESCO, 1989, vol II, p. 243).

Há algo no homem de natureza inconquistável, "desta vez uma parcela de nossa própria constituição psíquica” (FREUD, 1930, p. 105). E as instituições? Costumam excluir automaticamente as diferenças, único modo pelo qual a subjetividade comparece conforme demonstra a prática e a teoria psicanalítica. Assim, por estrutura, as instituições provocam o mal-estar em seus membros: enquanto instrumentos da civilização prometem a seus filhos ideais falicizados e bens supremos em detrimento do desejo. Este, ao contrário do que postulam certas correntes psicanalíticas, não possui nenhum objeto adequado (ordem da possibilidade). A satisfação prometida àqueles que seguem bem-comportados chega sob a forma da neurose, onde o sujeito se vê forçado a gozar daquilo que não serve para nada. 
Normatividade no lugar da singularidade, igualdade no lugar da diferença, complementariedades no lugar da falta.

Qual a demanda que se verifica, atualmente, na instituição psicanalítica, senão a de que os analistas abandonem a paixão pelo inconsciente em favor dos ideais sociais da instituição? Em troca, seus membros, ao se desviarem do investimento no saber, recebem toda uma sorte de bens imaginários que Ihe trazem a ilusão de ter conquistado a terra prometida. Identificados histericamente com o discurso da felicidade veiculado pela instituição, tomam-na enquanto concepção do mundo. Sustentam-se, então, neste tipo de demanda institucional, garantias ao eu, à pessoa do analista e consequentemente, também, ao sucesso da instituição em detrimento da verdade.

Constata-se, desse modo, o prevalecimento do discurso da histérica neste modelo institucional: sua estrutura evidencia a impotência do sujeito frente aquilo que o causa. Por ser constituir num Outro pleno que responde à demanda histérica de completude e saber absolutos, a instituição impede a emergência do desejo do analista e obstaculiza as análises pessoais de seus analistas na medida em que estes se agarram aos ganchos sociais oferecidos. O sujeito passa a ter na instituição o que Freud denominou de ganho secundário da doença: "reivindica por direito de sua neurose a piedade que o mundo lhe recusou [...] e pode então eximir-se da obrigação de combater sua pobreza por meio do trabalho" (LACAN, 1974, p.22). Não há como produzir na impotência a não ser de forma sintomática, como apelo. Compreende-se, então, porque a falta de produção teórica à qual nos referimos acima: no tamponamento que se faz ao real da falta de significante do Outro, o sintoma impede a emergência da angústia necessária para que o sujeito produza singularmente e amplie, no caso, o saber psicanalítico.

Um outro tipo de demanda institucional que se constata é a escravidão de seus membros a um mestre que, travestido de analista, valendo-se do discurso universitário (também reconhecido por alguns autores como o discurso do obsessivo) visa à univocidade e faz do outro um objeto (BOURGUIGNON, 1991, p. 26). O sujeito fica, então, fadado a enunciar mimeticamente o discurso daquele que reina na instituição, passando a não mais se interrogar sobre o desejo do Outro. O mestre, em questão, por não reconhecer a morte, ocupa o lugar de agente do discurso universitário e é equiparado à problemática do obsessivo, pois este, em seu repúdio ao feminino - 
lugar da falta - procura também anular as diferenças através de sua verdade, o falo. Pleno de poderes, ocupa de fato o lugar inocupável do saber do Outro, traduzido na empáfia, na arrogância discursiva que impede o caminho à simbolização do real.

O império das palavras vazias, sob a forma de jargões conceituais e técnicos, denunciam a obsessionalização da descoberta freudiana que desta forma fica impedida de ser transmitida. De novo, aqui, a estrutura da instituição protege os analistas de suas análises pessoais, pois o discurso institucional torna-se um sintoma inanalisável do analista, algo que não lhe traz conflito, muito pelo contrário, só certeza.

$\mathrm{Na}$ inflação de publicações com textos estereotipados, à qual temos acesso no mercado, percebe-se a falta de estilo daquele que escreveu, colocando em destaque a abolição de toda enunciação do sujeito em favor dos interesses do discurso dominante. O saber psicanalítico, aqui, é encarnado enquanto uma ideia religiosa produtora de sentido absoluto, portanto, ele é transformado num dialeto obsessivo, signo da falta de possibilidade de o analista sustentar o objeto da psicanálise enquanto causa.

Evidência imediata desta posição é a violência que se exerce no cotidiano institucional. Supostos donos da verdade, se "esqueceram" de que a interpretação vem do Outro e utilizando-se do que, hipnotizados, aprendem, praticam continuamente uma psicanálise silvestre, fugindo à sua ética, ao comprometimento do analista com a escuta do Outro. Aqui, cabe lembrarmos do aforisma lacaniano "a resistência é sempre do analista", utilizado para nos referirmos ao momento em que o analista, em sua prática, foge à regra fundamental de atenção flutuante, tomando o exercício de poder como técnica. Diante deste abuso interpretativo intra-institucional, por que não parodiarmos o Metre de Paris: "a instituição é que sempre resiste", ao escolher a prática do exercício de poder como sintoma. Infelizmente, por vezes, numa selvageria enlouquecida, sob o signo do ódio, a violência também se expressa na tentativa de difamação pública que se visa a atingir algum membro da instituição, em geral aquele que dela se desliga. Portanto, à ausência da ética psicanalítica junta-se a falta total daquela outra ética que atravessa qualquer grupo humano, desde os mais humildes até os mais sofisticados.

O que se evidencia como vimos, nestas duas modalidades institucionais aqui descritas, é que nelas a institucionalização da psicanálise liga-se diretamente à resistência que sofre seu objeto de transmissão. O discurso histérico e o discurso universitário, que situam em sua linha inferior a impotência, indicam que na instituição 
ocorre uma paralisação de descoberta freudiana pela elisão da articulação entre a falta do sujeito e a falta do Outro, provocando um sentido único e, portanto, empobrecedor do saber. Como não há esperança alguma de atingir o real pela representação, os bens e garantias, reforços dos engodos do narcisismo, tornam-se instrumentos da ideologia institucional para calar o discurso da psicanálise no seio da instituição. Da mesma forma, a doutrina, seja ela qual for, se tomada enquanto verdade absoluta, perderá sua condição simbólica, de abstração, tornando-se uma crença obsessiva que levará fatalmente à vitória da religião institucional sobre a psicanálise. Adiante-se, assim, na própria casa da psicanálise, a previsão lacaniana de que no futuro, provavelmente, a religião triunfará sobre a doutrina freudiana.

Os defensores de ambas as posições se dizem inimigos, e numa interminável luta de rivalidade especular limitam-se a acusar uns aos outros de não se constituírem como uma "verdadeira" instituição psicanalítica. Entretanto, não se permitem, jamais, embora todos sejam analistas, dar-se conta daquilo em que são semelhantes: a resistência contínua ao saber psicanalítico. Se de fato procurassem refletir sobre as semelhanças, poderiam fazer a expulsão de dentro de si daquilo que resiste a uma produção mais inovadora e mais respeitosa para com a própria psicanálise.

Fala-se muito, principalmente em nossos meios de comunicação, sobre a crise da psicanálise, mas esta questão é inteiramente falsa, já que não se pode falar da crise de uma ciência sem que se produza uma teoria que a refute em seus próprios fundamentos. A crise encontra-se, como vimos, nas próprias instituições psicanalíticas, que, submergidas aos avatares da civilização, tornam-se inimigas daquilo que deveriam proteger. A antinomia, a contradição inevitável que se choca com a razão, entre instituição e psicanálise, é evidentemente sustentada por outra questão, não menos importante: a crise dos próprios analistas, daqueles que se recusam a analisar a escolha, em que nada reconfortante, de ocupar o lugar de analista.

Freud vislumbrou o conforto que necessariamente se daria entre os analistas e psicanálise ao escrever a seu discípulo Laforgue: "Aturde-me, às vezes, que os próprios analistas não sejam radicalmente modificados por sua relação com a análise" (NICÉAS, 1988, p. 106). A perplexidade de Freud diante da falta de resolução dos analistas de suas próprias resistências indica que é preciso também operar, desde dentro da Instituição, uma desconstrução dos sintomas que nela emergem. 
Tal como o conto de Poe, "A carta roubada", ninguém vê: a psicanálise é a peste, sim, não está em crise e é mais forte do que o turbilhão mesquinho das demandas pessoais dos analistas os das exigências de status social da instituição psicanalítica.

\section{DA URGÊnCIA de Novos Espaços Desejantes}

Mas, então, o que é que se passa finalmente? Será que a psicanálise, além de ser uma profissão impossível, é uma causa fadada a fracassar dentro de suas instituições? Ou será que ela justamente vem demonstrar a impossibilidade das instituições de levarem adiante sua doutrina?

A psicanálise só não fracassará dentro de suas instituições se o discurso analítico vier a triunfar dentro delas, o que necessariamente se constituirá num paradoxo: o discurso analítico vem demonstrar que a psicanálise só poderá ganhar se perder, se não elidir o real com os efeitos do sucesso institucional. Porque, este, longe de ser referido a Das Ding, encontra-se a serviço da demanda da instituição e de seus membros.

Posto isto, podemos responder à segunda questão de modo afirmativo, constituindo-se esta resposta como mais uma ferida narcísica, desta vez particular, aos analistas: a institucionalização da psicanálise é da ordem do impossível, porque seu objeto de transmissão se revela incapturável, quer seja pelas manhas do imaginário ou pelas malhas do simbólico. Entretanto, Freud não autorizou aos psicanalistas veicularem a ideia do término das instituições, nem tampouco a ideia de uma instituição ideal. No texto Mal-estar na civilização, propõe uma Outra saída à civilização, e, portanto, para as instituições: a da ordem do desejo, pois ele que, como ninguém, soube nos falar da alma humana, sabe que "nem a renúncia às pulsões, nem a satisfação que nós possamos lhe trazer extinguem um mal-estar do desejo" (FREUD, 1930, p. 348).

Não se trata, então, de negar à psicanálise possibilidades de institucionalizarse, mas antes, fazer uma resistência a resistência à psicanálise e pensar sobre outras formas de sustentar seus significantes, outras maneiras possíveis de nos reunirmos em nome dela, talvez apenas com alguns pares, para reflexão sobre seus problemas cruciais e sua institucionalização. Cabe a nós nesse momento pensarmos na questão da formação do analista, isto é, na psicanálise em intensão e na psicanálise em 
extensão, não mais dissociados na própria história da psicanálise, pois muitas de suas "recordações encobridas" são signo do efeito de estrutura de nossas instituições e nos transmitem o que por anos viemos mantendo. Manter viva a memória histórica das instituições psicanalíticas para que a clausura do determinismo não impeça a emergência do novo na história da descoberta freudiana.

Criar novos espaços onde seja barrada a ideologia dos ganhos sociais e a totalização do saber que tornam nossas instituições psicanalíticas iguais às outras instituições - igreja, exército e partidos políticos. Assim, talvez seja possível testemunhar com produções fiéis a identidade da psicanálise, a diferença entre levar uma causa adiante e sua divulgação perversa. A resingularização da institucionalização da psicanálise só acontecerá com a criação deste novo espaço desejante, de absoluta alteridade, no qual seja permitido ao analista recriar constantemente o saber psicanalítico, pelo trabalho de "fazer incidir sobre o saber teórico da psicanálise, seus significantes primordiais, [resgatados em sua própria análise] através do que ele estará a produzir o real que perfura esta mesma teoria, a" (Coutinho Jorge, 1988, p. 213).

A institucionalização impossível da psicanálise deve levar à possibilidade de que a paixão pelo inconsciente possa de novo pulsar com vigor, e a psicanalise, assim, demonstrar ao mundo seu fracasso, signo de sua potência, que nada mais é do que a possibilidade de o sucesso do Inconsciente vir a se inscrever continuamente, ainda que não todo. É a transitoriedade do saber que a psicanálise aponta em sua prática e teoria. Tal como dizia Freud a respeito da vida, no texto "A Transitoriedade" (1914) a importância e a beleza da psicanalise residem justamente em seu caráter transitório. É no final desse lindo texto que encontramos a esperança pela via pulsional: "reconstruiremos tudo o que a guerra destruiu, e talvez em terreno mais firme e de forma mais duradoura do que antes". Ou seja: reconstruiremos tudo o que a resistência das instituições psicanalíticas desviou com relação à psicanalise, porque esta... insiste, não resiste. 


\section{REFERÊNCIAS}

BOURGUIGNON, A. O conceito de renegação em Freud, Jorge Zahar editor, RJ, 1991.

CHINALLI, M. “A chegada da peste: cem anos da viagem de Freud aos EUA (1909-2009)"

Arquivo Maaravi: Revista Digital de Estudos Judaicos da UFMG. Belo Horizonte, v. 4, n. 7, out. 2010. ISSN: 1982-3053. Disponível em: https://doi.org/10.17851/1982-3053.4.7.53-62 Consulta em: 25/11/2020.

COUTINHO JORGE, M. A. Sexo e Discurso. Rio de Janeiro: Jorge Zahar, 1988.

FREUD, S. Edição Standard Brasileira das Obras Psicológicas Completas de Sigmund Freud. Rio d Janeiro: Imago, 1976.

(1913c) Sobre o início do tratamento, vol. XI

(1914d) História do movimento psicanalítico, vol, XIV.

(1916a [1915] Sobre a Transitoriedade, vol. XIV.

(1930 [1929]) Mal-estar na Civilização, vol. XXI.

FREUD, S. (1926) "O valor da vida, uma entrevista rara de Freud”, in: O gabinete do Dr. Lacan. (orgs, Peter Gay, Philip Rief, Richard Wollheim). São Paulo: Brasiliense 1990.

FREUD, S. (1934/1939) O homem Moisés e o monoteísmo. Três ensaios. Porto Alegre. Editora LP\&M. 2014.

LACAN, J. (1965) Del Trieb de Freud y del deseo del psicoanalista. In: Escritos 2, Siglo XXI editores, Madri, 1985.

LACAN, J. (1967) Proposicio del 9 de octubre de 1967. In: Ornicar? Champ Freudien, Barcelona, 1981.

(1959-60) O seminário, livro 7, A ética da psicanálise. Rio de Janeiro: Jorge Zahar editor, RJ, 1988.

1982.

(1972-1974) O seminário, livro 20, Mais, ainda. Rio de Janeiro: Jorge Zahar, RS, 1986.

(1974) A Terceira. In: Che Vuoi?, ano um n. zero, Cooperativa Cultural J. Lacan,

NICÉAS, C. A. O freudismo do Cardeal e a ética dos psicanalistas. In: A ordem do Sexual, Editora Campus LTDA, 1988.

PRYGOGINE, I. \& STENGERS, I. A Nova Aliança: a metamorfose da ciência. Brasília, Editora Universidade de Brasília, DF, 1984. 
ROUDINESCO, E. História da Psicanálise na França. Vol. I e II. Rio de Janeiro: Jorge Zahar, 1989.

ROUDINESCO, E. \& PLON, M. Dicionário de psicanálise. Trad.: Vera Ribeiro, Lucy Magalhães. Rio de Janeiro: Jorge Zahar, 1998.

SOUFOUAN, M. J. Lacan - a questão da formação dos analistas. Porto Alegre: Artes Médicas 1985. 


\title{
PSYChOANALYTIC INSTITUTIONS AND THEIR \\ SYMPTOMATIC FORMATIONS
}

\begin{abstract}
The author addresses the theme of teaching and transmission of psychoanalysis from the famous phrase, attributed to Freud on the occasion of his arrival in the United States in 1909, "They do not know what we are bringing them: the plague", proposes to reflect on the symptomatic impasses of psychoanalyst institutions in the face of the reality of the unconscious.
\end{abstract}

KeYWORDS: Plague. Unconscious. Psychoanalytic Institution. Symptomatic Formations. 


\section{LES INSTITUTIONS PSYChANALYTIQUES ET LEURS FORMATIONS SYMPTOMATIQUES}

\section{RÉSUMÉ}

L'auteur aborde le thème de l'enseignement et de la transmission de la psychanalyse à partir de la célèbre phrase, attribuée à Freud à l'occasion de son arrivée aux États-Unis en 1909, "Ils ne savent pas ce que nous leur apportons : la peste ", propose de réfléchir aux impasses symptomatiques des institutions psychanalystes face à la réalité de l'inconscient.

MotS-CLÉs: Peste. Inconscient. Institution Psychanalytique, Formations Symptomatiques. 
RECEBIDO EM 28/08/2020

APROVADO EM 10/10/2020

C 2020 Psicanálise \& Barroco em revista

http://www.seer.unirio.br/index.php/psicanalise-barroco/index

revista@psicanaliseebarroco.pro.br

Programa de Pós-Graduação em Memória Social — UNIRIO

Memória, Subjetividade e Criação

www.memoriasocial.pro.br/proposta-area.php 